OPEN ACCESS

Edited by:

Hajo Dieringa,

Helmholtz Centre for Materials and Coastal Research (HZG), Germany

Reviewed by: Guntram Prof. Dr. Wagner,

Technische Universität

Chemnitz, Germany Sergey Mironov,

Belgorod National Research University, Russia

*Correspondence:

Renlong Xin

rlxin@cqu.edu.cn

Specialty section:

This article was submitted to

Structural Materials,

a section of the journal

Frontiers in Materials

Received: 28 June 2019 Accepted: 10 December 2019

Published: 09 January 2020

Citation:

Ren W, Xin R, Tan C and Liu D (2020) Texture Related Inhomogeneous

Deformation and Fracture Localization in Friction-Stir-Welded Magnesium Alloys: A Review. Front. Mater. 6:339.

doi: 10.3389/fmats.2019.00339

\section{Texture Related Inhomogeneous Deformation and Fracture Localization in Friction-Stir-Welded Magnesium Alloys: A Review}

\author{
Weijie Ren ${ }^{1}$, Renlong Xin ${ }^{1 *}$, Chuan Tan ${ }^{1}$ and Dejia Liu${ }^{2}$ \\ ${ }^{1}$ Joint International Laboratory for Light Alloys (MOE), College of Materials Science and Engineering, Chongqing University, \\ Chongqing, China, ${ }^{2}$ College of Materials Science and Engineering, East China Jiaotong University, Nanchang, China
}

Friction stir welding (FSW) is a solid-state joining technique, which can avoid surface distortion and grain coarsening, and is very suitable for the joining of magnesium (Mg) alloys. However, a pronounced and inhomogeneous deformation texture was usually formed in the stir zone (SZ) of Mg welds. This has significant effect on the joint strength and fracture behavior of FSW Mg joints. In this review, microstructure and texture evolutions in weld zone (WZ) are analyzed based on the electron backscatter diffraction (EBSD) data. Schmid factor (SF) changes for slip and extension twinning were observed and discussed. The localized plastic deformation and fracture mechanisms of Mg welds are analyzed. In addition, some methods for improving the joint strength of FSW Mg welds are tested. Finally, the research direction of FSW Mg alloys in the future is determined.

Keywords: friction stir welding, magnesium alloy, texture, localized deformation, fracture

\section{INTRODUCTION}

Mg alloys continue to receive significant interests in automotive and aerospace industries due to their obvious advantages of low density and high specific strength (Barnett et al., 2004; Suhuddin et al., 2009; Yang et al., 2010; Kainer, 2016; Dieringa, 2017). To widen their application, it is important to consider the advanced joining technology of Mg alloys (Lee et al., 2003; Xunhong and Kuaishe, 2006; Xie et al., 2007). Unfortunately, conventional fusion welding faces many challenges such as porosity, crack, intolerable distortions, emission of non-toxic fumes and evaporative loss of alloying elements (Commin et al., 2009; Cam, 2011). As a solid-state joining technique, friction stir welding (FSW) can avoid solidification problems associated with conventional fusion welding and has great potential in welding light metals such as Mg alloys (Woo et al., 2006; Lee et al., 2007; Afrin et al., 2008; Argade et al., 2012; Chen et al., 2013; He et al., 2014; Sidhar et al., 2016).

FSW was invented at the Welding Institute (TWI) of the United Kingdom in 1991, and it was initially applied to aluminum alloys (Thomas et al., 1991, 2003). During FSW, a non-consumable rotating probe is inserted into the abutting edges of the workpieces and traversed along the line of the joint (see Figure 1). The localized heating softens the materials around the probe. The combination of tool rotation and translation leads to movement of materials from the front to the back of the probe. Severe plastic deformation and friction heat in this process lead to dynamic recrystallization in weld zone (WZ), causing significant grain refinement (Freeney and Mishra, 2010; Xin et al., 2013b; Ni et al., 2014). Based on the basic principles of FSW, friction stir processing (FSP) technique was developed by Mishra et al. (1999) and Mishra and Mahoney (2001) mainly 


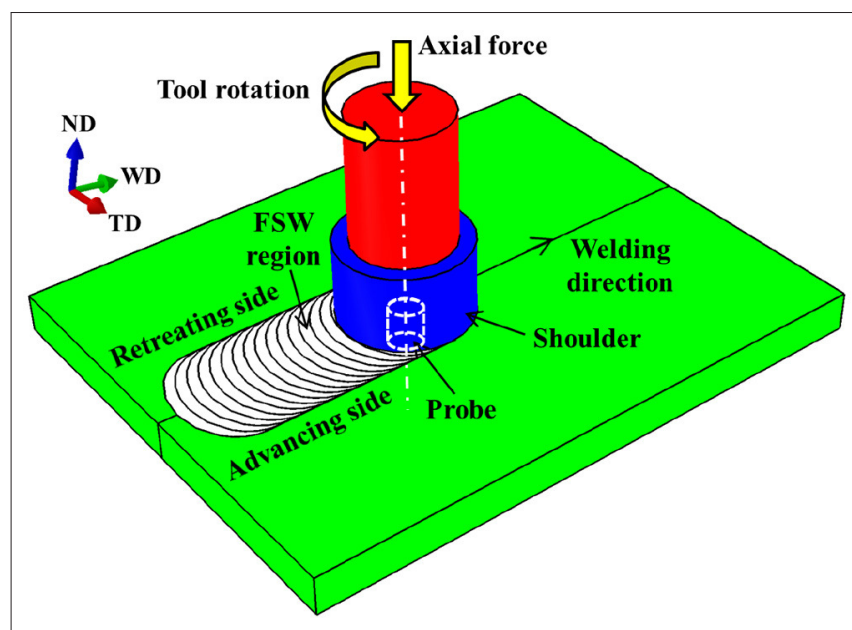

FIGURE 1 | Schematic illustration of the FSW process.

for the purpose of microstructure modification (Berbon et al., 2001; Bhargava et al., 2009; Cui et al., 2009; Yuan et al., 2011, 2013; Mansoor and Ghosh, 2012; Jain et al., 2013; Nene et al., 2018). Mohan et al. (2013) found that the average grain size of the FSP AZ91 alloy was $0.5 \mu \mathrm{m}$, which exhibits high strain rate superplasticity. The elongation of $1,251 \%$ was achieved at a strain rate of $1 \times 10^{-2} \mathrm{~s}^{-1}$ and temperature of $330^{\circ} \mathrm{C}$.

Previous studies confirmed that various series of $\mathrm{Mg}$ alloys, such as AZ (Mg-Al-Zn) (Afrin et al., 2007, 2008), AM (Mg$\mathrm{Al}-\mathrm{Mn}$ ) (Cavaliere and De Marco, 2007), and ZK (Mg-Zn-Zr) (Mironov et al., 2007; Xie et al., 2008) have been successfully joined by FSW. However, a pronounced and inhomogeneous texture with (0001) plane roughly parallel to the probe surface was generally formed in stir zone (SZ) (Park et al., 2003a,b; Woo et al., 2008; Xin et al., 2012). As well-known that Mg alloys have strong mechanical anisotropy due to the limited number of slip systems and the large difference of critical resolved shear stress (CRSS) among the various slip and twinning systems (Song et al., 2019). Therefore, the presence of strong local texture in SZ would cause severe non-uniform plastic deformation during transverse tensile tests on the $\mathrm{Mg}$ joint (Ma, 2008; Xin et al., 2013a; Liu et al., 2014). This significantly deteriorates the joint strength. In addition, it was found that fracture consistently initiates in the transition region between thermal-mechanical affected zone (TMAZ) and SZ-side on advancing side (Lim et al., 2005; Yang et al., 2010; Dorbane et al., 2016).

As seen from the above descriptions, WZ is the weak place for FSW Mg alloys. In-depth understandings on its mechanical property and deformation behavior are necessary for the wide application of $\mathrm{Mg}$ joints. In this paper, the localized plastic deformation and fracture mechanisms of $\mathrm{Mg}$ welds with typical micro-texture development are discussed. In addition, some methods for improving the joint performance are tested. Finally, the research direction on FSW Mg alloys is determined.

\section{PROPERTIES AND DEFORMATION MECHANISMS OF FSW MG JOINT}

\section{Texture and Joint Strength}

Figure 2 demonstrates the evolution of complicated microtexture in the WZ of an FSP $\mathrm{Mg}$ alloy (Xin et al., 2010). The base material (BM) has an initial basal texture with the c-axis of most grains parallel to normal direction (ND). A localized strong basal texture is formed in SZ and it tends to tilt from transverse direction (TD) to processing direction (PD) with the position moving from SZ-side to SZ-center. This is mainly related to the shear stress generated by the rotation of the cylindrical probe surface (Park et al., 2003a). Moreover, the $<0001>$ direction tends to tilt to ND at upper and bottom sections of SZ. The formation of $<0001>/ / N D$ texture in the upper and bottom sections is attributable to the stirring effect of the tool shoulder and the probe tip, respectively. The texture in TMAZ was also affected by the stir probe, which is more diffuse compared to that in $\mathrm{BM}$, and the $<0001>$ direction was tilted toward TD. The $<0001>$ texture in heat affected zone (HAZ) is similar to that in BM, but more diffuse. The $<0001>$ direction in crown zone (CZ) slightly deviates from ND due to the stress from the tool shoulder.

The complicated texture distribution in $\mathrm{Mg}$ welds has strong influences on joint performance (Xin et al., 2013a; Liu et al., 2014; Moraes et al., 2017). As shown in Figure 3, the yield strength (YS) and ultimate tensile strength (UTS) of an FSP AZ31 alloy are much lower along TD than that of the as-received plate (Xin et al., 2012). Moreover, the elongation of the former is obviously decreased. The mechanical properties of several kinds of FSW Mg alloys [AZ31 (Yang et al., 2010; Xin et al., 2014; Ugender, 2018), AZ61 (Park et al., 2003b; Singh et al., 2018), ZK60 (Xie et al., 2008), ZM21 (Harikrishna et al., 2010), and Mg-Zn-Y-Zr (Xie et al., 2007)] were further summarized, as shown in Figure 4. It is seen that the YS and UTS of FSW Mg alloys are generally lower than that of BM. Therefore, it is desirable to understand the effects of textural variation in $\mathrm{Mg}$ welds on joint strength and the underlying plastic deformation mechanism.

\section{Inhomogeneous Deformation of Joint}

It is seen from Figure 5A that the $\mathrm{Mg}$ alloy joint has suffered severe non-uniform macroscopic plastic deformation (Xin et al., 2012). To estimate the inhomogeneity of plastic deformation, the thickness and width reductions in the different regions were measured and are presented in Figure 5B. It reveals that SZside experienced the largest deformation, while SZ-center and HAZ experienced the least deformation. Consequently, necking was observed in SZ-side. Xin et al. (2012) calculated the Schmid factor (SF) maps for an FSP AZ31 plate based on EBSD data, as shown in Figure 5C. It is seen that SZ-side has the largest mean SF $(\sim 0.40)$ for basal slip, while SZ-center has the lowest $(\sim 0.14)$. Considering basal slip is the most easily activated deformation mode for Mg alloy at room temperature (RT), the SF analysis indicates that SZ-side is the softest and SZ-center is the hardest during transverse tensile tests. This is consistent with the observed inhomogeneous deformation for $\mathrm{Mg}$ joints as shown in Figure 5B. The grains in SZ-center, TMAZ, and HAZ are 


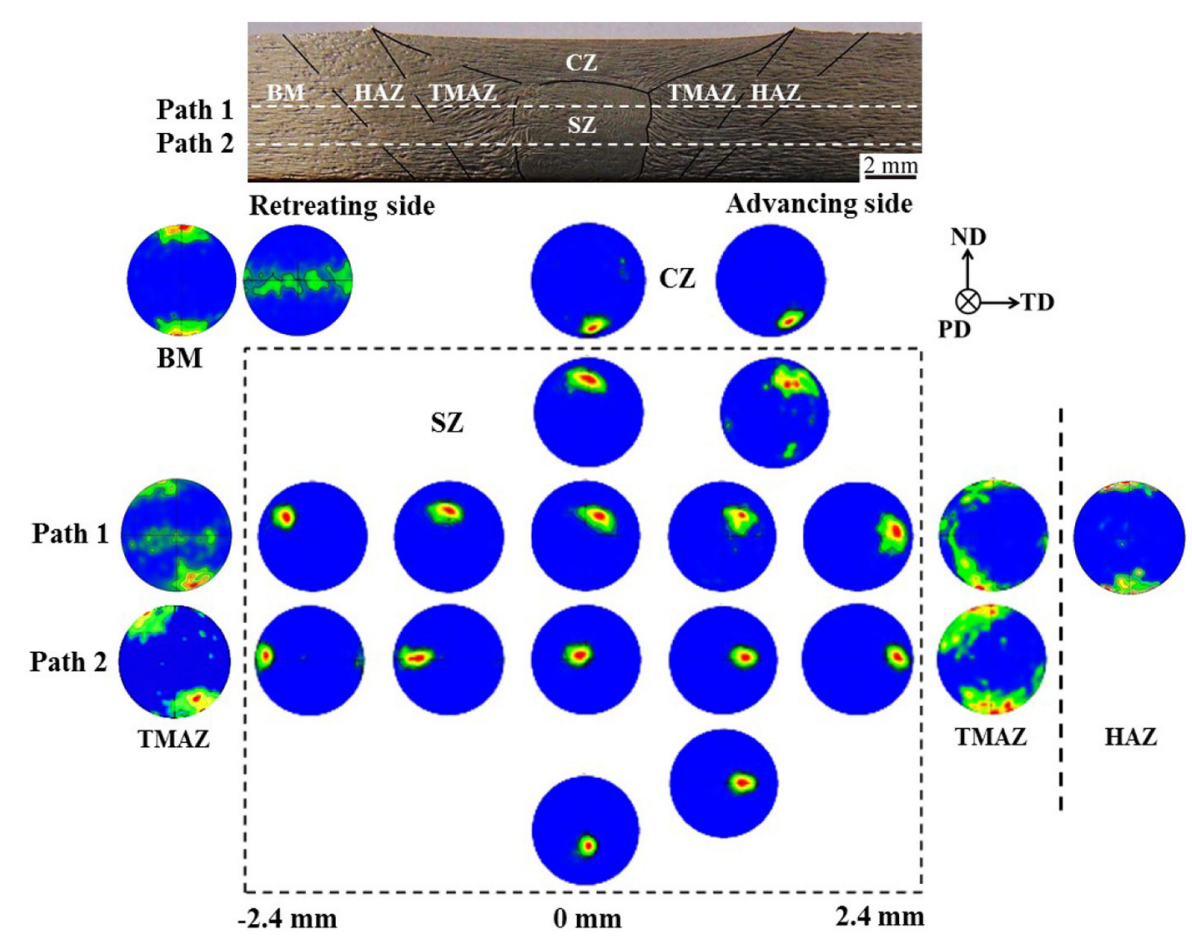

FIGURE 2 | Overall cross-sectional macrostructure of the FSP AZ31 Mg alloy and the \{0002\} pole figures in various regions of the joint (Xin et al., 2010) (Copyright $\odot$ 2010, Trans Tech Publications Ltd.).

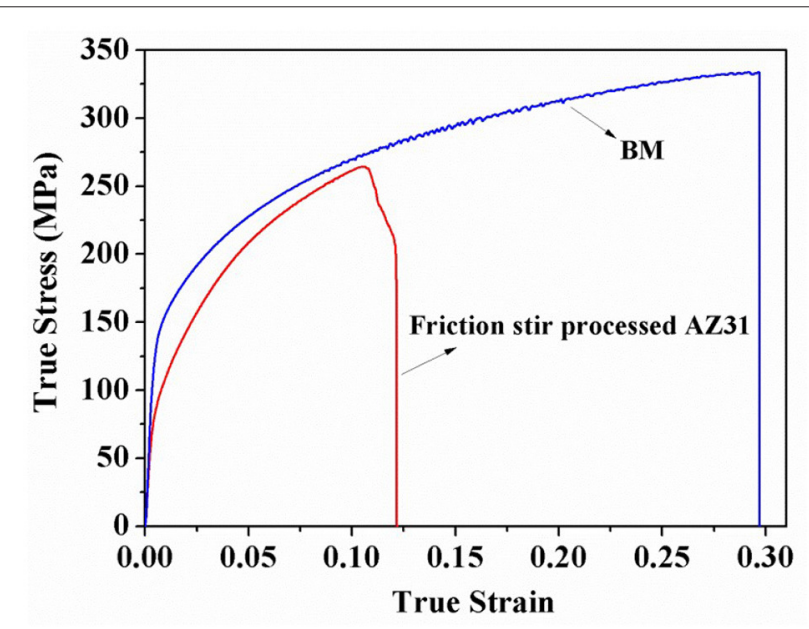

FIGURE 3 | Stress-strain curves of the transverse tensile specimen cut from the BM and the FSP AZ31 Mg alloy (Xin et al., 2012) (Copyright $\odot$ 2012, Springer Nature).

oriented favorable for prismatic slip and $c+$ a slip. However, these slip modes have high CRSS, and hence are difficult to activate at RT. Thus, the profuse activation of basal slip should be an important factor for necking in SZ-side.

It is known that $\{10-12\}$ extension twinning is also an important deformation mode for $\mathrm{Mg}$ alloys because of its low CRSS (Barnett, 2007; Lin et al., 2016). Besides, twinning activity is highly dependent on grain orientations with respect to the loading direction. As shown in Figure 6A, few extension twin boundaries were observed in SZ-center and there is no obvious peak around $86^{\circ}$ in the misorientation angle distribution. On the contrary, considerable twin boundaries are identified in SZside (Figure 6B) and the corresponding misorientation angle distribution indicates that there is a strong peak around $86^{\circ}$. This implies that the profuse activation of extension twinning is also responsible for the necking occurred in SZ-side. Theoretical calculation, however, indicates that the strain accommodated by extension twinning is very limited (Barnett, 2007). On the other hand, basal slip can continuously accommodate the applied plastic strain. Therefore, it is considered that the strain localization occurred in SZ is mainly attributed to basal slip. In addition, the profuse activation of basal slip and extension twinning in SZ-side is an important reason for the lower YS and UTS of the joint compared to BM.

Many studies found that an "embossed" phenomenon appears in SZ-center during the transverse tensile tests on FSW Mg joints (Xin et al., 2013a; Liu et al., 2014). Prangnell and Heason (2005) and Yang et al. (2014b) attributed this to the different sheared material layers between the two sides of the specimen. However, Xin et al. (2013a) believed that the activation of basal slip in SZ-side was a major factor for the formation of this "embossed phenomenon." The reasons for this behavior are complicated and further studies are certainly required.

It is difficult to observe the material flow in SZ during the actual welding process. Numerical simulation can help overcome 

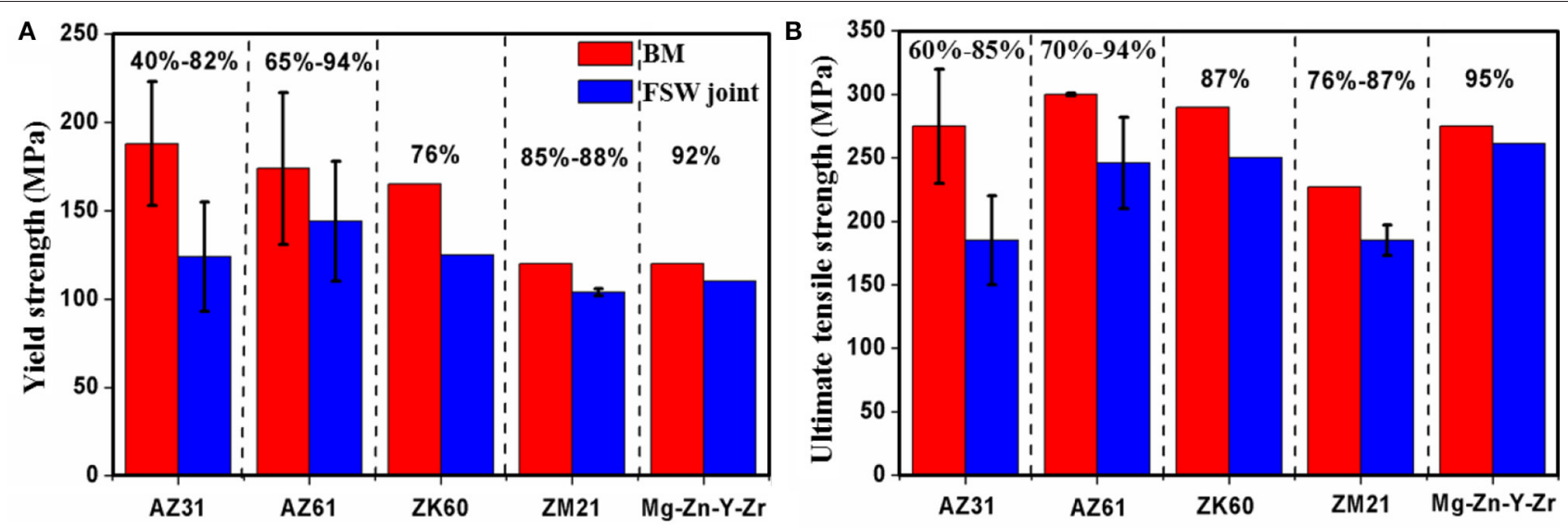

FIGURE 4 | Summary of the mechanical properties of FSW Mg alloys: (A) YS and (B) UTS.

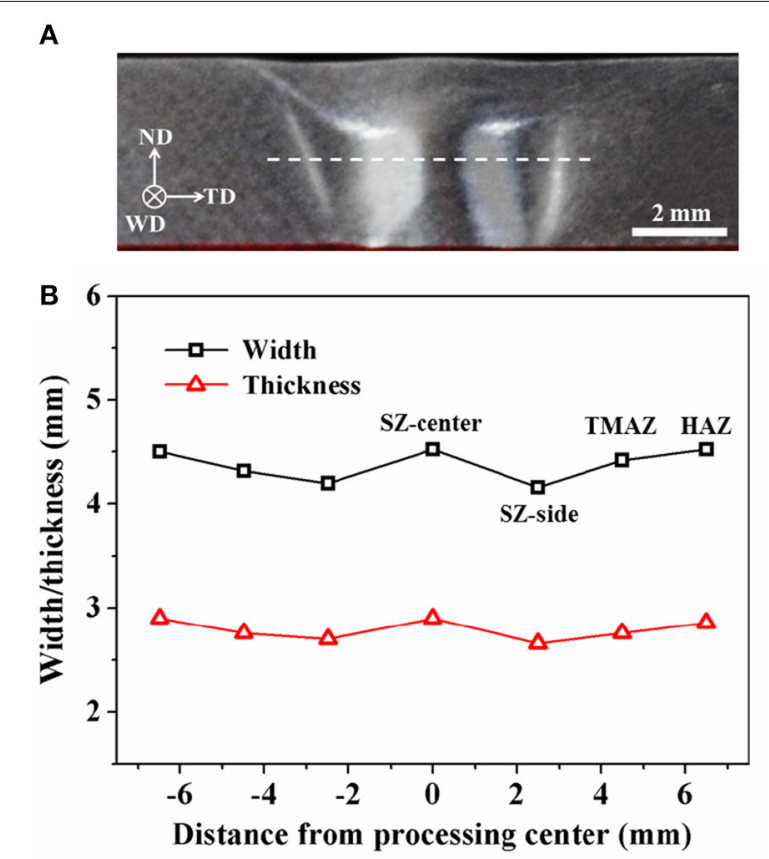

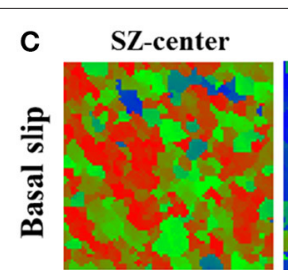
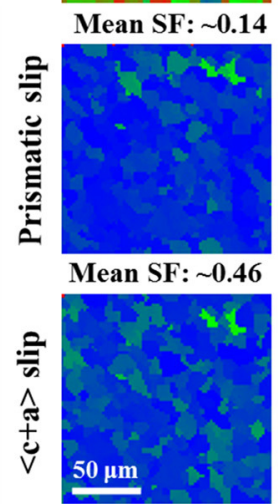

Mean SF: $\sim 0.44$

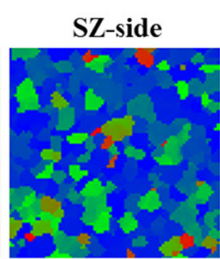

$\sim \mathbf{0 . 4 0}$

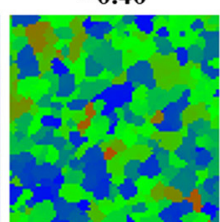

$\sim 0.31$

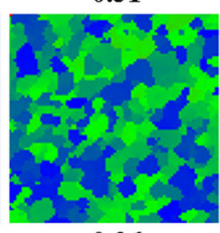

$\sim 0.36$

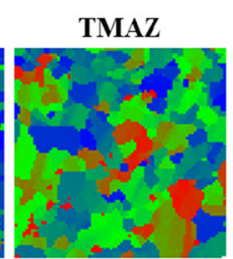

$\sim 0.29$

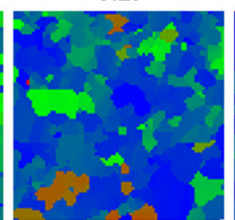

$\sim 0.39$

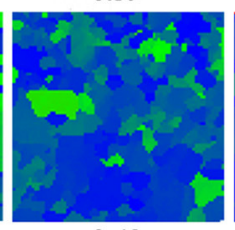

$\sim 0.42$

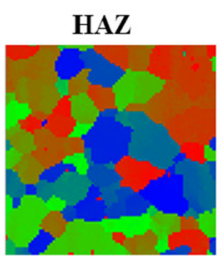

$\sim 0.23$

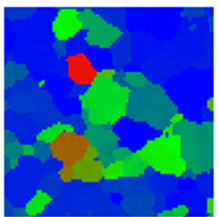

$\sim 0.40$

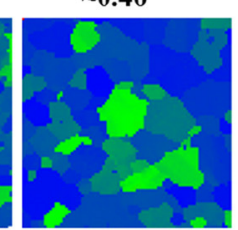

$\sim 0.41$

Distance from processing center ( $\mathrm{mm}$ )

FIGURE 5 | (A) Macrograph of the Mg weld after transverse tensile test; (B) measured with width and thickness at different sub-regions of the FSP AZ31 Mg alloy after tensile fracture. The original width and thickness of tensile samples were 5 and $3 \mathrm{~mm}$, respectively; (C) SF maps of the various regions of the Mg weld (Xin et al., 2012) (Copyright () 2012, Springer Nature).

this problem (Yu et al., 2012; Baffari et al., 2018; Iqbal et al., 2019). For example, the material flow and temperature field (Nandan et al., 2006) near the probe surface have been predicted and the mechanical response (Chiumenti et al., 2013) have been analyzed during FSW process. Kim et al. (2017) simulated the texture evolution in SZ of AZ31 Mg alloys during FSW process using a visco-plastic self-consistent (VPSC) polycrystal model. Ren et al. (2019) developed a crystal plasticity finite element model (CPFEM) to simulate the localized deformation of an FSW AZ31 Mg joint during bending. They confirmed that the strongly localized texture in conjunction with the different activities of slip and twinning in each sub-region cause the severe strain heterogeneity in welding direction (WD). Moreover, the localized deformation of FSW Mg alloys during transverse tensile test have been analyzed by digital image correlation (DIC) technique (Mironov et al., 2017) and surface depth measurement (Liu et al., 2014). In their study, a random ink pattern was applied on sample surface and the movement of the ink pattern during test was recorded by a high speed digital camera. Then, the in-plane Lagrangian strains can be obtained by the DIC technique. 

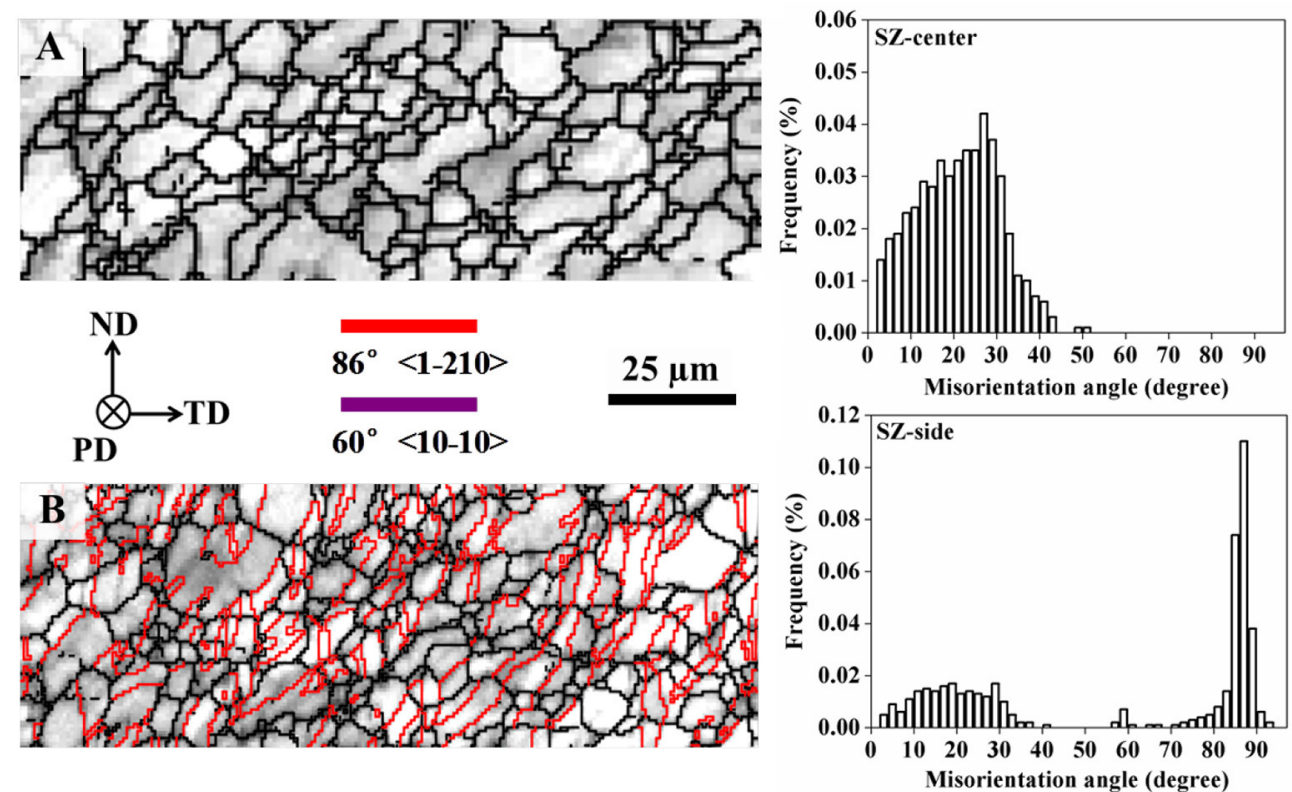

FIGURE 6 | EBSD orientation maps of the (A) SZ-center and (B) SZ-side after 5\% strain along TD and the corresponding misorientation angle distributions (Xin et al., 2012) (Copyright () 2012, Springer Nature).

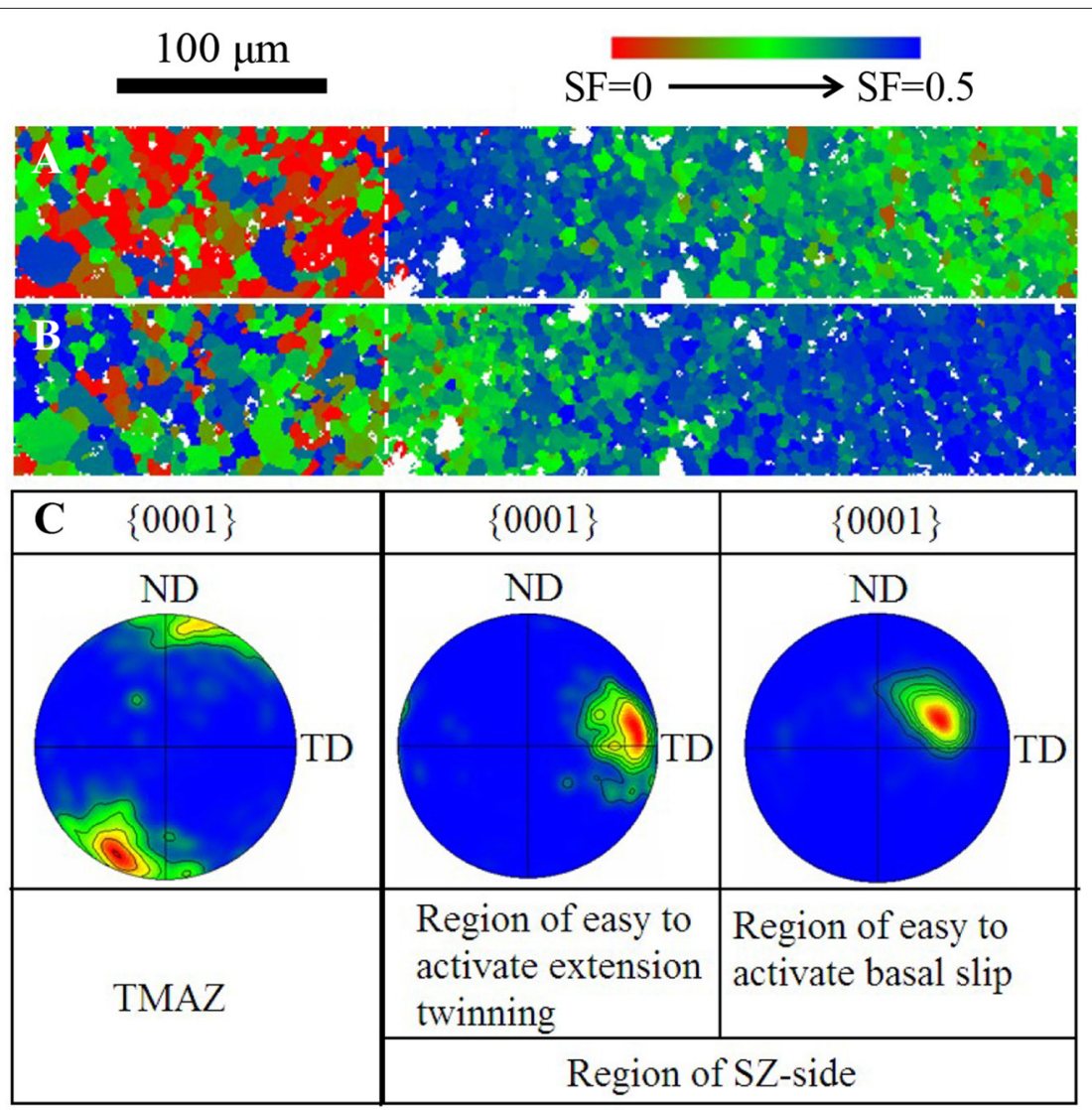

FIGURE 7 | SF maps of deformation mechanisms for tension along TD at the transition region between TMAZ and SZ-side on AS (Xin et al., 2013a): (A) extension twinning, (B) basal slip; (C) $\{0001\}$ pole figures at the transition zone (Copyright @ 2013 , ELSEVIER S.A.). 


\section{Fracture Mechanisms}

The fracture behavior of FSW/FSP Mg alloys is a hot topic of current research. Extensive studies indicate that fracture consistently initiates in the transition region between SZ and TMAZ on advancing side (AS) (Lim et al., 2005; Fu et al., 2012). It was found that fracture initiated in $S Z$ where the grains were oriented favorable for basal slip (Park et al., 2003b; Woo et al., 2006). Some researchers further revealed that extension twinning activated at SZ-side can accelerate fracture (Xin et al., 2012). Some other researchers attributed fracture initiation to the incompatible plastic deformation at TMAZ/SZ interface where texture sharply changed (Xin et al., 2010, 2012; Yang et al., 2010; Shang et al., 2017a).

As seen from the above reports, the transition zone is a weak place. Therefore, it is necessary to have an in-depth understanding on the deformation behavior of this region. Figure 7 shows the SF maps for extension twinning and basal slip based on the EBSD data in transition region on AS (Xin et al., 2013a). The SF maps were obtained by an in-house program developed by Xin. For each orientation, six twin variants were considered and the maximum SF was taken to color the maps. If the strain generated by the twin is opposite in direction to that of the imposed strain, the SF was assigned zero. Figure 7A reveals that a narrow region $(\sim 100 \mu \mathrm{m})$ in SZ-side, close to SZ/TMAZ interface has the highest SF for extension twinning. A relatively wide region in SZ-side, slightly away from the SZ/TMAZ interface shows the highest SF for basal slip (Figure 7B). Based on the SF maps, SZ-side was divided into two micro-regions (Xin et al., 2013a). One is the Easy to Activate Extension Twinning (EAET) region and the other is the Easy to Activate Basal Slip (EABS) region. In addition, the SF for extension twinning in TMAZ is lower than that in EAET, showing a boundary in the transition region. $\{0001\}$ pole figures of various micro-regions are presented in Figure 7C, indicating that the caxis is nearly parallel to TD in EAET region, while it is inclined $\sim 40^{\circ}$ toward TD in EABS region. The $<0001>$ direction was

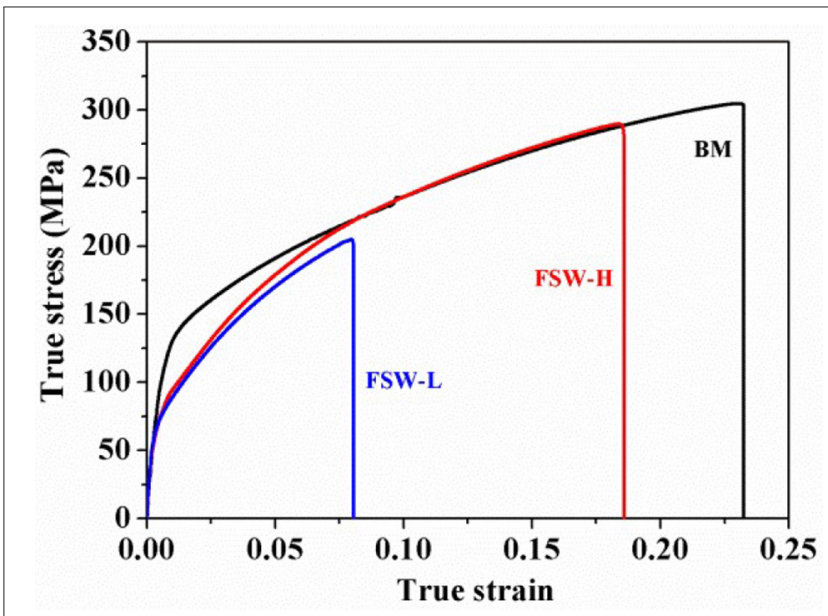

FIGURE 9 | Stress-strain curves of the as-received plate and FSW AZ31 Mg alloys (Xin et al., 2016) (Copyright (c 2016, ELSEVIER BV).
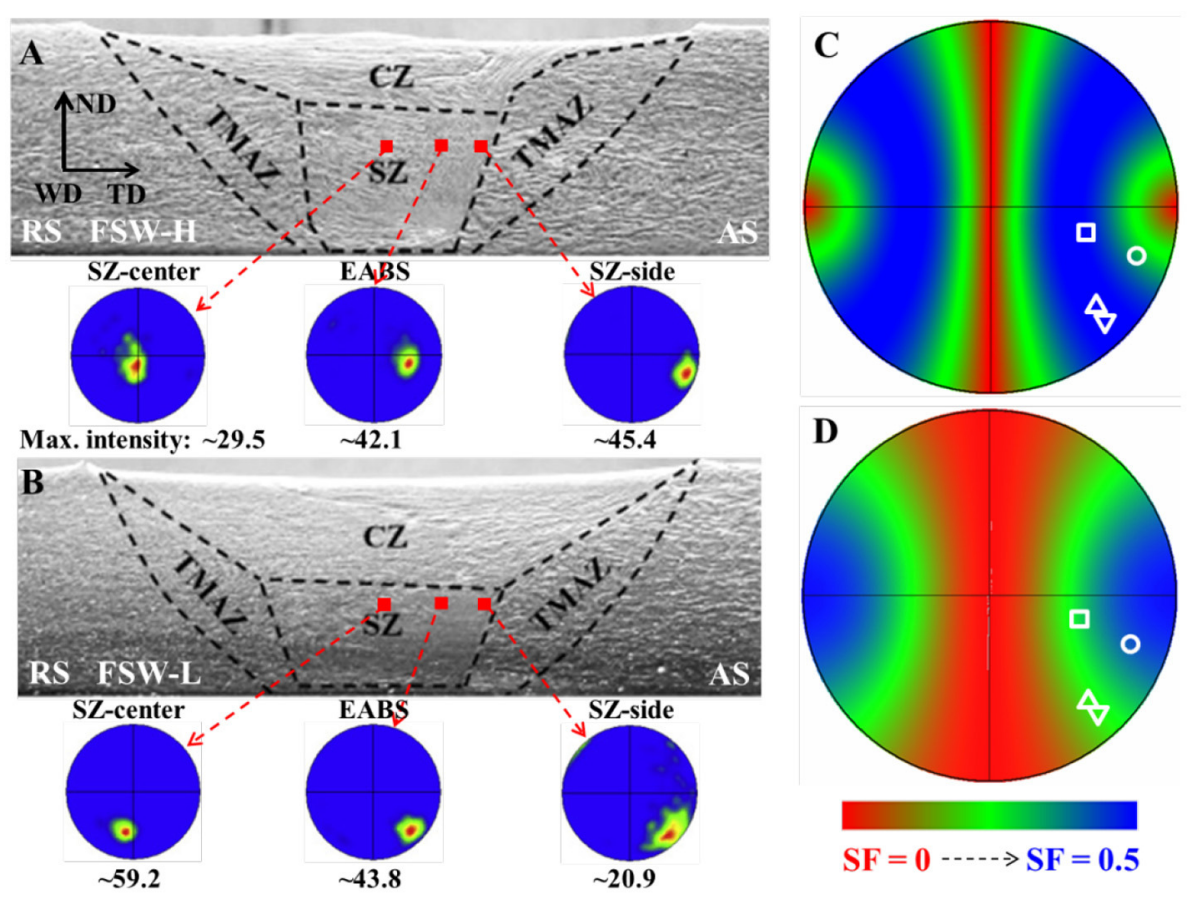

FIGURE 8 | \{0001\} pole figures for different regions in the SZ of (A) FSW-H joint and (B) FSW-L joint (Xin et al., 2016); (0001) pole figures showing the calculated SF for (C) basal slip and (D) extension twinning. The region close to SZ-side and SZ-side in FSW-H and FSW-L joints are superimposed on the pole figures and indicated by $\square, \circ, \Delta$, and, $\nabla$ respectively (Copyright $\odot$ 2016, ELSEVIER BV). 
tilted $\sim 25^{\circ}$ clockwise to ND in TMAZ. This sharp texture change in each micro-region might cause deformation incompatibility and initiate fracture (Xin et al., 2010).

Recently, Liu et al. (2016a) reported that a triple junction region existed among TMAZ, CZ and SZ in AS, but it was not evident in RS. Drastic texture changes were found among the triple regions. They concluded that the significant SF differences among the different parts are the evidences for deformation incompatibility. This accelerated fracture in the triple junction region in AS. However, some researchers found that fracture also initiates in RS during transverse tensile test on FSW AZ31 Mg alloys (Liu et al., 2015). They attributed this rare situation to the easier activation of basal slip in RS than AS, which caused more severe strain localization in RS. In addition, Mironov et al. (2017) studied the tensile behaviors of FSW AZ31 alloys along TD using EBSD and DIC technique, and found that failure initiates at the weld root and originates from $\{10-11\}-\{10-12\}$ double twinning.

\section{WAYS TO IMPROVE THE JOINT STRENGTH}

The complex texture distribution in FSW Mg joints largely deteriorates the joint strength and hinders their widespread application (Lim et al., 2005). Therefore, great efforts have been devoted to improve the joint performance. It was found that welding parameters such as weld speed and rotation rate can control heat input and modify grain size and texture of an FSW joint (Commin et al., 2009; Padmanaban et al., 2010; Yang et al., 2010, 2013; Liu et al., 2011; Chowdhury et al., 2013; Hütsch et al., 2014; Pan et al., 2016; Rao et al., 2016; Alireza Askariani et al., 2017; Richmire et al., 2018). So, it is possible to improve the joint strength by varying welding parameters. Shang et al. (2017b) indicated that the non-uniform deformation of FSW AZ31 Mg joints can be suppressed by modifying the texture distribution through increasing the tool rotation rate, which then improved the tensile strength and ductility. Xu et al. (2018) joined AZ31 plates by FSW with an extremely low welding speed and rotation rate. They found that the strong texture is randomized in the whole WZ and the strength of FSW Mg joints was enhanced without ductility loss.

Xin et al. (2016) joined AZ31 plates by FSW with two types of welding parameters, and these were referred to as $\mathrm{FSW}-\mathrm{H}$ joint (rotation rate of $1,600 \mathrm{rpm}$ and welding speed of $600 \mathrm{~mm} / \mathrm{min}$ ) and FSW-L joint (rotation rate of $800 \mathrm{rpm}$ and welding speed of $90 \mathrm{~mm} / \mathrm{min}$ ), respectively. They found that welding parameters largely affected the texture distribution in SZ (Figures 8A,B). The $\mathrm{c}$-axis is nearly parallel to the WD-TD plane in FSW$\mathrm{H}$ joint, while it was rotated away from the WD-TD plane in FSW-L joint. Moreover, high welding speed and rotation

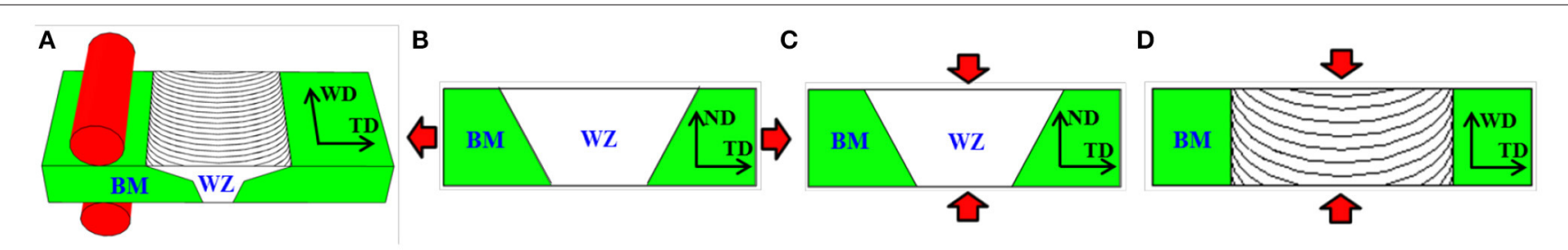

FIGURE 10 | Schematic illustration of the post-weld deformation of FSW AZ31 Mg alloys: (A) rolling, (B) tension along TD, (C) compression along ND, (D) compression along WD.
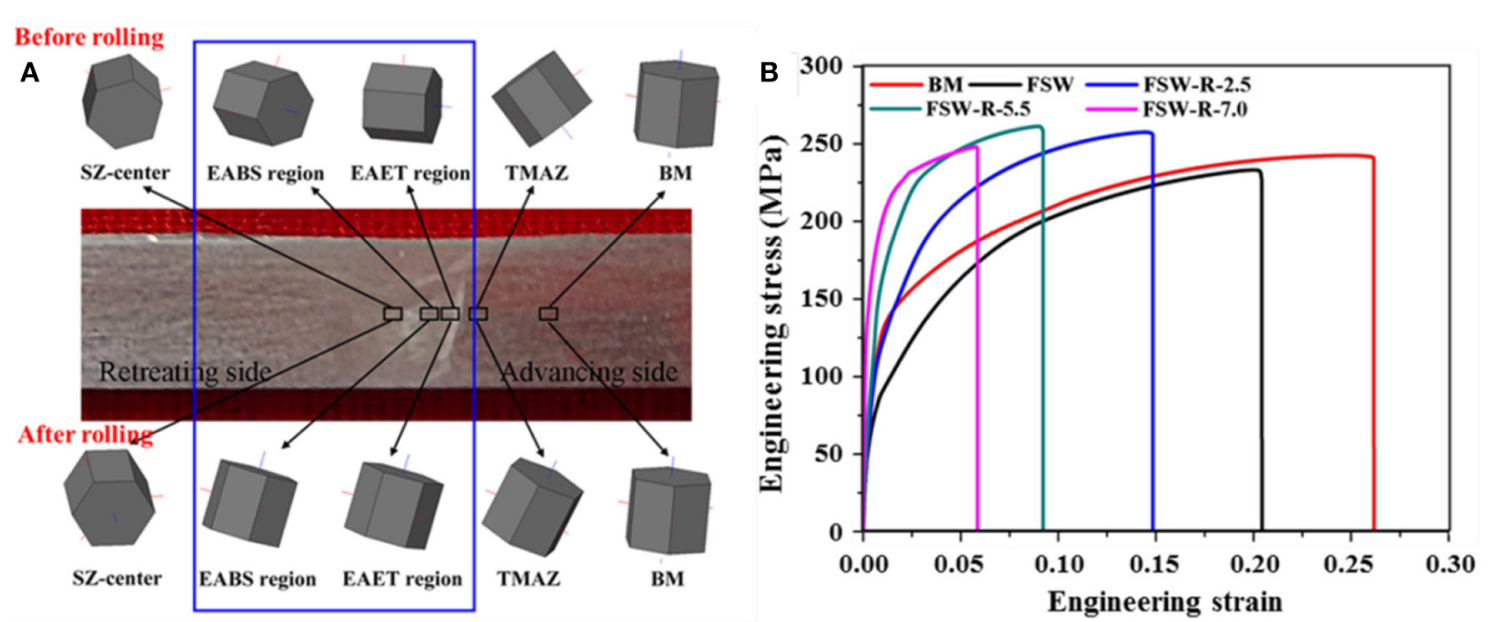

FIGURE 11 | (A) Schematic illustration of the changes of crystallographic orientation after subsequent rolling process for FSW AZ31 Mg alloy; (B) stress-strain curves of the transverse tensile tests (Xin et al., 2013b) (Copyright (c) 2013, ELSEVIER S.A.). 
rate increased the size of SZ and decreased the size of $\mathrm{CZ}$. The SF distributions for basal slip (Figure 8C) and extension twinning (Figure 8D) were calculated as a function of (0001) pole orientation. The tensile stress along TD was assumed for the calculation. It shows that for FSW-H joint, the grains in SZside are favorable for extension twinning and the grains in the region close to SZ-side are favorable for basal slip. While for FSW-L joint, the grains in both areas are more favorable for basal slip. As a consequence, the activation ability of basal slip and extension twinning was changed, which therefore influence the joint strength, inhomogeneous plastic deformation and fracture behaviors. The stress-strain curves of the as-received plate and AZ31 Mg alloy joints are displayed in Figure 9. It shows that the YS is almost the same for the two kinds of Mg joints, lower than that for BM. However, the elongation and UTS of the FSW-H joint increased compared to that of FSW-L joint.

Because of the strong anisotropic mechanical properties of $\mathrm{Mg}$ alloys, texture control post-weld deformation could be another effective way to improve the joint strength of FSW/FSP $\mathrm{Mg}$ alloys. Lee et al. (2007) reported that a post compressive strain of $\sim 6 \%$ could largely raise the YS of an FSP Mg plate, which was attributed mainly to texture strengthening. Rolling (Figure 10A) (Xin et al., 2013b), tension (Figure 10B) (Xin et al., 2014) and compression (Figures 10C,D) (Liu et al., 2016b) have been applied on FSW AZ31 Mg alloys to improve their joint strength. For brevity, only post-weld rolling is discussed in the following.

The change of crystallographic orientations in FSW AZ31 Mg plate during post-weld rolling is illustrated in Figure 11A. It is clear that drastic grain reorientation was induced by extension twinning especially in EABS and EAET regions after rolling. The twinned grains have a texture with the caxis nearly parallel to ND, i.e., the applied stress direction. Figures 8C,D indicate that this c-axis//ND texture is hard for the activation of basal slip and extension twinning during tension along TD. So from texture strengthening point of view, post-rolling will greatly increase the transverse tensile strength of SZ-side. The stress-strain curves along TD before and after post-rolling are presented in Figure 11B. As expected, all of the specimens with subsequent rolling exhibit much larger tensile stress compared with the FSWundeformed specimen.

Recently, Shang et al. (2019) found that the strength of FSW AZ31 Mg joints can be significantly improved by an additional pass of FSP. The YS of the joint was enhanced from $96 \mathrm{MPa}$ (original FSW joint) to $122 \mathrm{MPa}$ and the tensile strength

\section{REFERENCES}

Afrin, N., Chen, D. L., Cao, X., and Jahazi, M. (2007). Strain hardening behavior of a friction stir welded magnesium alloy. Scr. Mater. 57, 1004-1007. doi: 10.1016/j.scriptamat.2007.08.001

Afrin, N., Chen, D. L., Cao, X., and Jahazi, M. (2008). Microstructure and tensile properties of friction stir welded AZ31B magnesium alloy. Mater. Sci. Eng. A 472, 179-186. doi: 10.1016/j.msea.2007.03.018

Alireza Askariani, S., Pishbin, H., and Moshref-Javadi, M. (2017). Effect of welding parameters on the microstructure and mechanical properties of the friction increased to be roughly equal to that of BM with no reduction of elongation. The shape of the welding tool also influences the joint strength (Mishra and Ma, 2005). Yang et al. (2010) indicates that the tensile strength of FSW AZ31 Mg joints tended to increase with increasing the shoulder diameter and the elongation was significantly improved. Chen et al. (2013) joined an AZ31B $\mathrm{Mg}$ alloy by a double-sided FSW technique, and found that the elongation of the joint increased from 18 to $28 \%$ with similar tensile strength as the original FSW. They attributed this improved ductility to the relatively random crystallographic texture in the double-sided FSW joint. Furthermore, some researchers found that the joint strength of FSW Mg alloys can be improved by subsequent aging treatment (Yang et al., 2014a).

\section{SUMMARY AND OUTLOOK}

As a solid-state process, FSW can avoid solidification problems and therefore has great potential in welding of $\mathrm{Mg}$ alloys. However, strong texture is usually formed in $\mathrm{Mg}$ joints, which results in localized plastic deformation, and significantly deteriorates the mechanical properties of welds. This paper discussed the inhomogeneous deformation and fracture mechanisms of FSW/FSP $\mathrm{Mg}$ joints with typical texture distributions. In addition, some methods to improve the joint performance of FSW Mg alloys are tested.

The traditional experimental approaches are insufficient for the study of the deformation mechanism of $\mathrm{Mg}$ joints such as the "embossed phenomenon" in SZ-center and fracture localization. CPFEM coupled with twin reorientation, fracture criterion and grain size effect would be an effective mean for studying nonuniform plastic strain and fracture behaviors of FSW Mg joint in the future. Exploring simple and efficient methods to modify the textures in WZ, thereby improving the joint performance is also an interesting research direction.

\section{AUTHOR CONTRIBUTIONS}

WR and RX wrote the paper. CT and DL revised the paper.

\section{FUNDING}

This project was financially supported by the National Key Research and Development Program of China (2016YFB0301102) and the National Natural Science Foundation of China (Project Nos. 51571045, 51871036, and 51421001). 
Barnett, M. R. (2007). Twinning and the ductility of magnesium alloys: part II. "Contraction" twins. Mater. Sci. Eng. A 464, 8-16. doi: 10.1016/j.msea.2007.02.109

Barnett, M. R., Keshavarz, Z., Beer, A. G., and Atwell, D. (2004). Influence of grain size on the compressive deformation of wrought Mg-3Al-1Zn. Acta Mater. 52, 5093-5103. doi: 10.1016/j.actamat.2004. 07.015

Berbon, P. B., Bingel, W. H., Mishra, R. S., Bampton, C. C., and Mahoney, M. W. (2001). Friction stir processing: a tool to homogenize nanocomposite aluminum alloys. Scr. Mater. 44, 61-66. doi: 10.1016/S1359-6462(00)00578-9

Bhargava, G., Yuan, W., Webb, S. S., and Mishra, R. S. (2009). Influence of texture on mechanical behavior of friction-stir-processed magnesium alloy. Metall. Mater. Trans. A 41, 13-17. doi: 10.1007/s11661-009-0079-8

Cam, G. (2011). Friction stir welded structural materials: beyond Al-alloys. Int. Mater. Rev. 5656, 1-48. doi: 10.1179/095066010X12777205875750

Cavaliere, P., and De Marco, P. P. (2007). Friction stir processing of AM60B magnesium alloy sheets. Mater. Sci. Eng. A 462, 393-397. doi: 10.1016/j.msea.2006.04.150

Chen, J., Fujii, H., Sun, Y., Morisada, Y., and Ueji, R. (2013). Fine grained $\mathrm{Mg}-3 \mathrm{Al}-1 \mathrm{Zn}$ alloy with randomized texture in the double-sided friction stir welded joints. Mater. Sci. Eng. A 580, 83-91. doi: 10.1016/j.msea.2013.05.044

Chiumenti, M., Cervera, M., Agelet De Saracibar, C., and Dialami, N. (2013). Numerical modeling of friction stir welding processes. Comput. Method Appl. Mech. Eng. 254, 353-369. doi: 10.1016/j.cma.2012.09.013

Chowdhury, S. H., Chen, D. L., Bhole, S. D., Cao, X., and Wanjara, P. (2013). Friction stir welded AZ31 magnesium alloy: microstructure, texture, and tensile properties. Metall. Mater. Trans. A 44, 323-336. doi: $10.1007 / \mathrm{s} 11661-012-1382-3$

Commin, L., Dumont, M., Masse, J. E., and Barrallier, L. (2009). Friction stir welding of AZ31 magnesium alloy rolled sheets: influence of processing parameters. Acta Mater. 57, 326-334. doi: 10.1016/j.actamat.2008.09.011

Cui, G. R., Ma, Z. Y., and Li, S. X. (2009). The origin of non-uniform microstructure and its effects on the mechanical properties of a friction stir processed Al-Mg alloy. Acta Mater. 57, 5718-5729. doi: 10.1016/j.actamat.2009.07.065

Dieringa, H. (2017). Influence of cryogenic temperatures on the microstructure and mechanical properties of magnesium alloys: a review. Metals 7:38. doi: $10.3390 /$ met7020038

Dorbane, A., Ayoub, G., Mansoor, B., Hamade, R. F., Kridli, G., Shabadi, R., et al. (2016). Microstructural observations and tensile fracture behavior of FSW twin roll cast AZ31 Mg sheets. Mater. Sci. Eng. A 649, 190-200. doi: 10.1016/j.msea.2015.09.097

Freeney, T. A., and Mishra, R. S. (2010). Effect of friction stir processing on microstructure and mechanical properties of a cast-magnesium-rare earth alloy. Metall. Mater. Trans. A 41, 73-84. doi: 10.1007/s11661-009-0080-2

Fu, R. D., Ji, H. S., Li, Y. J., and Liu, L. (2012). Effect of weld conditions on microstructures and mechanical properties of friction stir welded joints on AZ31B magnesium alloys. Sci. Technol. Weld. Join. 17, 174-179. doi: 10.1179/1362171811Y.0000000056

Harikrishna, K. L., Dilip, J. J. S., Ramaswamy Choudary, K., Subba Rao, V. V., Koteswara Rao, S. R., Janaki Ram, G. D., et al. (2010). Friction stir welding of magnesium alloy ZM21. Trans. Indian Inst. Metals 63, 807-811. doi: $10.1007 / \mathrm{s} 12666-010-0123-9$

He, X., Gu, F., and Ball, A. (2014). A review of numerical analysis of friction stir welding. Prog. Mater. Sci. 65, 1-66. doi: 10.1016/j.pmatsci.2014.03.003

Hütsch, L. L., Hütsch, J., Herzberg, K., Dos Santos, J. F., and Huber, N. (2014). Increased room temperature formability of $\mathrm{Mg} \mathrm{AZ} 31$ by high speed friction stir processing. Mater. Des. 54, 980-988. doi: 10.1016/j.matdes.2013.08.108

Iqbal, M. P., Jain, R., and Pal, S. K. (2019). Numerical and experimental study on friction stir welding of aluminum alloy pipe. J. Mater. Process. Tech. 274:116258. doi: 10.1016/j.jmatprotec.2019.116258

Jain, V., Mishra, R. S., Verma, R., and Essadiqi, E. (2013). Superplasticity and microstructural stability in a $\mathrm{Mg}$ alloy processed by hot rolling and friction stir processing. Scripta. Mater. 68, 447-450. doi: 10.1016/j.scriptamat.2012.11.009

Kainer, K. U. (2016). "Challenges for implementation of magnesium into more applications," in Magnesium Technology 2016, eds A. Singh, K. Solanki, M. V. Manuel, and N. R. Neelameggham (Cham: Springer International Publishing), 5-6.
Kim, M. S., Jung, J. Y., Song, Y. M., and Choi, S. H. (2017). Simulation of microtexture developments in the stir zone of friction stir-welded AZ31 Mg alloys. Int. J. Plast. 94, 24-43. doi: 10.1016/j.ijplas.2017.02.013

Lee, C. J., Huang, J. C., and Du, X. H. (2007). Improvement of yield stress of friction-stirred $\mathrm{Mg}-\mathrm{Al}-\mathrm{Zn}$ alloys by subsequent compression. Scr. Mater. 56, 875-878. doi: 10.1016/j.scriptamat.2007. 01.041

Lee, W. B., Yeon, Y. M., and Jung, S. B. (2003). Joint properties of friction stir welded AZ31B- H24 magnesium alloy. Mater. Sci. Technol. 19, 785-790. doi: $10.1179 / 026708303225001867$

Lim, S., Kim, S., Lee, C.-G., Kim, S. J., and Yim, C. D. (2005). Tensile behavior of friction-stir-welded AZ31-H24 Mg alloy. Metall. Mater. Trans. A 36, 1609-1612. doi: 10.1007/s11661-005-0252-7

Lin, J. B., Ren, W. J., and Wang, X. Y. (2016). Research on the tensioncompression asymmetry of as-extruded ZK60 magnesium alloys at room temperature. Acta. Metall. Sin. 52, 264-270. doi: 10.11900/0412.1961.2015. 00324

Liu, D., Nishio, H., and Nakata, K. (2011). Anisotropic property of material arrangement in friction stir welding of dissimilar Mg alloys. Mater. Des. 32, 4818-4824. doi: 10.1016/j.matdes.2011.06.020

Liu, D., Xin, R., Xiao, Y., Zhou, Z., and Liu, Q. (2014). Strain localization in friction stir welded magnesium alloy during tension and compression deformation. Mater. Sci. Eng. A 609, 88-91. doi: 10.1016/j.msea.2014.04.089

Liu, G., Xin, R., Li, J., Liu, D., and Liu, Q. (2015). Fracture localisation in retreating side of friction stir welded magnesium alloy. Sci. Technol. Weld. Join. 20, 378-384. doi: 10.1179/1362171815Y.0000000027

Liu, Z., Xin, R., Li, D., Sun, L., and Liu, Q. (2016b). Comparative study on twinning characteristics during two post-weld compression paths and their effects on joint enhancement. Sci Rep. 6:39779. doi: 10.1038/srep39779

Liu, Z., Xin, R., Liu, D., Shu, X., and Liu, Q. (2016a). Textural variation in triple junction region of friction stir welded $\mathrm{Mg}$ alloys and its influence on twinning and fracture. Mater. Sci. Eng. A 658, 185-191. doi: 10.1016/j.msea.2016.01.097

Ma, Z. Y. (2008). Friction stir processing technology: a review. Metall. Mater. Trans. A 39, 642-658. doi: 10.1007/s11661-007-9459-0

Mansoor, B., and Ghosh, A. K. (2012). Microstructure and tensile behavior of a friction stir processed magnesium alloy. Acta Mater. 60, 5079-5088. doi: 10.1016/j.actamat.2012.06.029

Mironov, S., Motohashi, Y., Ito, T., Goloborodko, A., Funami, K., and Kaibyshev, R. (2007). Feasibility of friction stir welding for joining and microstructure refinement in a ZK60 magnesium alloy. Mater. Trans. 48, 3140-3148. doi: 10.2320/matertrans.MRA2007177

Mironov, S., Onuma, T., Sato, Y. S., Yoneyama, S., and Kokawa, H. (2017). Tensile behavior of friction-stir welded AZ31 magnesium alloy. Mater. Sci. Eng. A 679, 272-281. doi: 10.1016/j.msea.2016.10.036

Mishra, R. S., and Ma, Z. Y. (2005). Friction stir welding and processing. Mat. Sci. Eng. R 50, 1-78. doi: 10.1016/j.mser.2005.07.001

Mishra, R. S., and Mahoney, M. W. (2001). Friction stir processing: a new grain refinement technique to achieve high strain rate superplasticity in commercial alloys. Mater. Sci. Forum 357, 507-514. doi: 10.4028/www.scientific.net/MSF.357-359.507

Mishra, R. S., Mahoney, M. W., Mcfadden, S. X., Mara, N. A., and Mukherjee, A. K. (1999). High strain rate superplasticity in a friction stir processed 7075 Al alloy. Scr. Mater. 42, 163-168. doi: 10.1016/S1359-6462(99)0 $0329-2$

Mohan, A., Yuan, W., and Mishra, R. S. (2013). High strain rate superplasticity in friction stir processed ultrafine grained $\mathrm{Mg}-\mathrm{Al}-\mathrm{Zn}$ alloys. Mater. Sci. Eng. A 562, 69-76. doi: 10.1016/j.msea.2012.11.026

Moraes, J. F. C., Rodriguez, R. I., Jordon, J. B., and Su, X. (2017). Effect of overlap orientation on fatigue behavior in friction stir linear welds of magnesium alloy sheets. Int. J. Fatigue 100, 1-11. doi: 10.1016/j.ijfatigue.2017.02.018

Nandan, R., Roy, G. G., Lienert, T. J., and Debroy, T. (2006). Numerical modelling of 3D plastic flow and heat transfer during friction stir welding of stainless steel. Sci. Technol. Weld. Join. 11, 526-537. doi: 10.1179/174329306X1 07692

Nene, S. S., Zellner, S., Mondal, B., Komarasamy, M., Mishra, R. S., Brennan, R. E., et al. (2018). Friction stir processing of newly-designed Mg-5Al-3.5Ca-1Mn (AXM541) alloy: microstructure evolution and mechanical properties. Mater. Sci. Eng. A 729, 294-299. doi: 10.1016/j.msea.2018.05.073 
Ni, D. R., Chen, D. L., Yang, J., and Ma, Z. Y. (2014). Low cycle fatigue properties of friction stir welded joints of a semi-solid processed AZ91D magnesium alloy. Mater. Des. 56, 1-8. doi: 10.1016/j.matdes.2013.10.081

Padmanaban, G., Balasubramanian, V., and Sarin Sundar, J. K. (2010). Influences of welding processes on microstructure, hardness, and tensile properties of AZ31B magnesium alloy. J. Mater. Eng. Perform. 19, 155-165. doi: $10.1007 / \mathrm{s} 11665-009-9389-7$

Pan, F., Xu, A., Deng, D., Ye, J., Jiang, X., Tang, A., et al. (2016). Effects of friction stir welding on microstructure and mechanical properties of magnesium alloy Mg-5Al-3Sn. Mater. Des. 110, 266-274. doi: 10.1016/j.matdes.2016.07.146

Park, S. H. C., Sato, Y. S., and Kokawa, H. (2003a). Basal plane texture and flow pattern in friction stir weld of a magnesium alloy. Metall. Mater. Trans. A 34, 987-994. doi: 10.1007/s11661-003-0228-4

Park, S. H. C., Sato, Y. S., and Kokawa, H. (2003b). Effect of micro-texture on fracture location in friction stir weld of Mg alloy AZ61 during tensile test. Scr. Mater. 49, 161-166. doi: 10.1016/S1359-6462(03)00210-0

Prangnell, P. B., and Heason, C. P. (2005). Grain structure formation during friction stir welding observed by the 'stop action technique'. Acta Mater. 53, 3179-3192. doi: 10.1016/j.actamat.2005.03.044

Rao, H. M., Ghaffari, B., Yuan, W., Jordon, J. B., and Badarinarayan, H. (2016). Effect of process parameters on microstructure and mechanical behaviors of friction stir linear welded aluminum to magnesium. Mater. Sci. Eng. A 651, 27-36. doi: 10.1016/j.msea.2015.10.082

Ren, W., Xin, R., and Liu, D. (2019). Modeling the strongly localized deformation behavior in a magnesium alloy with complicated texture distribution. Mater. Sci. Eng. A 762:138103. doi: 10.1016/j.msea.2019.138103

Richmire, S., Hall, K., and Haghshenas, M. (2018). Design of experiment study on hardness variations in friction stir welding of AM60 Mg alloy. J. Magnes. Alloy. 6, 215-228. doi: 10.1016/j.jma.2018.07.002

Shang, Q., Ni, D. R., Xue, P., Xiao, B. L., and Ma, Z. Y. (2017a). Evolution of local texture and its effect on mechanical properties and fracture behavior of friction stir welded joint of extruded Mg-3Al-1Zn alloy. Mater. Char. 128, 14-22. doi: 10.1016/j.matchar.2017.03.018

Shang, Q., Ni, D. R., Xue, P., Xiao, B. L., and Ma, Z. Y. (2017b). Improving joint performance of friction stir welded wrought $\mathrm{Mg}$ alloy by controlling non-uniform deformation behavior. Mater. Sci. Eng. A 707, 426-434. doi: 10.1016/j.msea.2017.09.084

Shang, Q., Ni, D. R., Xue, P., Xiao, B. L., Wang, K. S., and Ma, Z. Y. (2019). $\mathrm{An}$ approach to enhancement of $\mathrm{Mg}$ alloy joint performance by additional pass of friction stir processing. J. Mater. Process. Technol. 264, 336-345. doi: 10.1016/j.jmatprotec.2018.09.021

Sidhar, H., Martinez, N. Y., Mishra, R. S., and Silvanus, J. (2016). Friction stir welding of Al-Mg-Li 1424 alloy. Mater. Des. 106, 146-152. doi: 10.1016/j.matdes.2016.05.111

Singh, K., Singh, G., and Singh, H. (2018). Investigation of microstructure and mechanical properties of friction stir welded AZ61 magnesium alloy joint. $J$. Magnes. Alloys 6, 292-298. doi: 10.1016/j.jma.2018.05.004

Song, B., Yang, Q., Zhou, T., Chai, L., Guo, N., Liu, T., et al. (2019). Texture control by $\{10-12\}$ twinning to improve the formability of $\mathrm{Mg}$ alloys: a review. J. Mater. Sci. Technol. 35, 2269-2282. doi: 10.1016/j.jmst.2019.03.045

Suhuddin, U. F. H. R., Mironov, S., Sato, Y. S., Kokawa, H., and Lee, C. W. (2009). Grain structure evolution during friction-stir welding of AZ31 magnesium alloy. Acta Mater. 57, 5406-5418. doi: 10.1016/j.actamat.2009.07.041

Thomas, W. M., Johnson, K. I., and Wiesner, C. S. (2003). Friction stir weldingrecent developments in tool and process technologies. Adv. Eng. Mater. 5, 485-490. doi: 10.1002/adem.200300355

Thomas, W. M., Nicholas, E. D., Needham, J. C., Murch, M. G., Templesmith, P., and Dawes, C. J. (1991). Friction Stir Butt Welding. International Patent Application No. PCT/GB92/02203, Great Britain Patent Application No. 9125978.8.

Ugender, S. (2018). Influence of tool pin profile and rotational speed on the formation of friction stir welding zone in AZ31 magnesium alloy. J. Magnes. Alloys 6, 205-213. doi: 10.1016/j.jma.2018.05.001

Woo, W., Choo, H., Brown, D. W., Liaw, P. K., and Feng, Z. (2006). Texture variation and its influence on the tensile behavior of a friction-stir processed magnesium alloy. Scr. Mater. 54, 1859-1864. doi: 10.1016/j.scriptamat.2006.02.019

Woo, W., Choo, H., Prime, M. B., Feng, Z., and Clausen, B. (2008). Microstructure, texture and residual stress in a friction-stir-processed AZ31B magnesium alloy. Acta Mater. 56, 1701-1711. doi: 10.1016/j.actamat.2007.12.020
Xie, G. M., Ma, Z. Y., and Geng, L. (2008). Effect of microstructural evolution on mechanical properties of friction stir welded ZK60 alloy. Mater. Sci. Eng. A 486, 49-55. doi: 10.1016/j.msea.2007.08.043

Xie, G. M., Ma, Z. Y., Geng, L., and Chen, R. S. (2007). Microstructural evolution and mechanical properties of friction stir welded $\mathrm{Mg}-\mathrm{Zn}-\mathrm{Y}-\mathrm{Zr}$ alloy. Mater. Sci. Eng. A 471, 63-68. doi: 10.1016/j.msea.2007.03.041

Xin, R., Li, B., Liao, A., Zhou, Z., and Liu, Q. (2012). Correlation between texture variation and transverse tensile behavior of friction-stir-processed AZ31 Mg alloy. Metall. Mater. Trans. A 43, 2500-2508. doi: 10.1007/s11661-012-1080-1

Xin, R., Liu, D., Li, B., Sun, L., Zhou, Z., and Liu, Q. (2013a). Mechanisms of fracture and inhomogeneous deformation on transverse tensile test of friction-stir-processed AZ31 Mg alloy. Mater. Sci. Eng. A 565, 333-341. doi: 10.1016/j.msea.2012.12.053

Xin, R., Liu, D., Shu, X., Li, B., Yang, X., and Liu, Q. (2016). Influence of welding parameter on texture distribution and plastic deformation behavior of as-rolled AZ31 Mg alloys. J. Alloys Compd. 670, 64-71. doi: 10.1016/j.jallcom.2016.02.023

Xin, R., Liu, D., Xu, Z., Li, B., and Liu, Q. (2013b). Changes in texture and microstructure of friction stir welded $\mathrm{Mg}$ alloy during post-rolling and their effects on mechanical properties. Mater. Sci. Eng. A 582, 178-187. doi: 10.1016/j.msea.2013.06.005

Xin, R., Sun, L., Liu, D., Zhou, Z., and Liu, Q. (2014). Effect of subsequent tension and annealing on microstructure evolution and strength enhancement of friction stir welded Mg alloys. Mater. Sci. Eng. A 602, 1-10. doi: 10.1016/j.msea.2014.02.062

Xin, R. L., Li, B., and Liu, Q. (2010). Microstructure and texture evolution during friction stir processing of AZ31 Mg alloy. Mater. Sci. Forum 654, 1195-1200. doi: 10.4028/www.scientific.net/MSF.654-656.1195

Xu, N., Song, Q., Fujii, H., Bao, Y., and Shen, J. (2018). Mechanical properties' modification of large load friction stir welded AZ31B Mg alloy joint. Mater. Lett. 219, 93-96. doi: 10.1016/j.matlet.2018.02.099

Xunhong, W., and Kuaishe, W. (2006). Microstructure and properties of friction stir butt-welded AZ31 magnesium alloy. Mater. Sci. Eng. A 431, 114-117. doi: 10.1016/j.msea.2006.05.128

Yang, J., Ni, D. R., Wang, D., Xiao, B. L., and Ma, Z. Y. (2014a). Friction stir welding of as-extruded $\mathrm{Mg}-\mathrm{Al}-\mathrm{Zn}$ alloy with higher $\mathrm{Al}$ content. Part II: influence of precipitates. Mater. Char. 96, 135-141. doi: 10.1016/j.matchar.2014.08.001

Yang, J., Ni, D. R., Xiao, B. L., and Ma, Z. Y. (2014b). Non-uniform deformation in a friction stir welded $\mathrm{Mg}-\mathrm{Al}-\mathrm{Zn}$ joint during stress fatigue. Int. J. Fatigue 59, 9-13. doi: 10.1016/j.ijfatigue.2013.10.004

Yang, J., Wang, D., Xiao, B. L., Ni, D. R., and Ma, Z. Y. (2013). Effects of rotation rates on microstructure, mechanical properties, and fracture behavior of Friction Stir-Welded (FSW) AZ31 magnesium alloy. Metall. Mater. Trans. A 44, 517-530. doi: 10.1007/s11661-012-1373-4

Yang, J., Xiao, B. L., Wang, D., and Ma, Z. Y. (2010). Effects of heat input on tensile properties and fracture behavior of friction stir welded $\mathrm{Mg}-3 \mathrm{Al}-1 \mathrm{Zn}$ alloy. Mater. Sci. Eng. A 527, 708-714. doi: 10.1016/j.msea.2009.09.044

Yu, Z., Zhang, W., Choo, H., and Feng, Z. (2012). Transient heat and material flow modeling of friction stir processing of magnesium alloy using threaded tool. Metall. Mater. Trans. A 43, 724-737. doi: 10.1007/s11661-011$0862-1$

Yuan, W., Mishra, R. S., Carlson, B., Mishra, R. K., Verma, R., and Kubic, R. (2011). Effect of texture on the mechanical behavior of ultrafine grained magnesium alloy. Scripta. Mater. 64, 580-583. doi: 10.1016/j.scriptamat.2010. 11.052

Yuan, W., Panigrahi, S. K., and Mishra, R. S. (2013). Achieving high strength and high ductility in friction stir-processed cast magnesium alloy. Metall. Mater. Trans. A 44, 3675-3684. doi: 10.1007/s11661-013$1744-5$

Conflict of Interest: The authors declare that the research was conducted in the absence of any commercial or financial relationships that could be construed as a potential conflict of interest.

Copyright $\odot 2020$ Ren, Xin, Tan and Liu. This is an open-access article distributed under the terms of the Creative Commons Attribution License (CC BY). The use, distribution or reproduction in other forums is permitted, provided the original author(s) and the copyright owner(s) are credited and that the original publication in this journal is cited, in accordance with accepted academic practice. No use, distribution or reproduction is permitted which does not comply with these terms. 